\title{
Research on the internal cause and correlative factor of virtual enterprises
}

\author{
$\mathrm{Hu} \mathrm{Yi}$ \\ School of economics, Huazhong Normal University, \\ 152 Luoyu Road, whan, P.R.China, 430079 \\ hy197105@126.com
}

\begin{abstract}
This paper makes use of a vertical integration model to explain virtual enterprises, analyses respective characteristics of virtual operation and internal integration, probes into the correlative factors of virtual operation. The paper points out that virtual operation and internal integration are two parallel ways which enterprises may choose to expand their organization. Virtual operation urges exterior market to become perfect, so may overcome the problem of market failure. Virtual operation can construct a relatively perfect exterior market, also uses existing exterior market efficiently, so enterprises are able to control market and transaction through virtual operation. But effective virtual operation is restricted by many conditions. The correlative factors of virtual enterprises includes the interior conditions of enterprises and exterior conditions from the dimensionalities of micro-environment and macro-environment. Therefore, along with the changes of market, environment, competition and enterprises' strategy, being agile and taking dynamic integration or virtual operation should be the best policy of enterprises' organization.
\end{abstract}

\section{Introduction}

Nowadays the advantage of virtual enterprises and virtual operation has been proven by lots of theory and practice. In the theory of competition and cooperation[1], the competition among enterprises has experienced antagonistical competition, tolerant competition and cooperative competition. Since the market environment is changeable, the cooperative competition among enterprises, which can be formed through organizing alliance to resist market risk, broadening market space, and complementing mutual advantage can swell competitive advantage of enterprises. In the strategic mode of virtual operation enterprises can share and exchange information to reduce costs of trading, harmonizing and management, can broaden 
cooperative scope of enterprises external, and can accomplish complex cooperation with the characteristic of close coupling of cooperation. Moreover, cooperation appears as shared knowledge and resources. Knowledge is one of the most important factors of production, and its feature of cumulative results in ability shortage of individual enterprise in changeable market. Resource partaking of capital, technology, market, information and management can remedy shortage of resources. As mentioned above, cooperative competition of virtual operation brings about its strategic advantage. In the theory of transaction cost[2], market or enterprises is a mode of resource allocation, and there is transaction cost in either of them. With complication of trading, transaction cost will be added continuously. However, enterprises can interiorize its trading to reduce transaction cost, which can acts as the main mode of resource allocation. The expansion of enterprise size will add transaction cost such as management costs to turn enterprises as hyper-marketing contractual organization operating virtually. To a certain degree, virtual enterprises, a kind of contractual organization, can remedy imperfection of contracts to resist market risk. These theories demonstrate the functions of virtual operation enough.

The virtual operation has brought the change of the enterprises' form. Charles $P$. Kindleberger[3], one of the founders of theory of monopolistic advantage, even already no longer regarded the modern $\mathrm{TNC}$ as the single manufacturer in the traditional microeconomics. He thought that the modern TNC was the unified firm by no means, it was the loose agglomerations of profit centers which were composed by the local certain profit centers in different countries. The view manifested the trend of enterprises' network and virtual organization.

However, so far the study on the internal cause and correlative factors of virtual enterprises is deficient. Why do enterprises implement virtual operation? What are the conditions of virtual operation? This paper will make some theoretical analysis on the internal cause and correlative factors of virtual enterprises in virtue of a vertical integrated model.

\section{A model to explain virtual enterprises and virtual operation}

A vertical integrated model is built to analyze the internal cause of virtual enterprises in this paper.

Consider a partial market with supplier A and enterprise B, supplier A provides raw material $X$ which enterprise $B$ needs, quantity of $X$ is the $x$, production cost is $\mathrm{C}(\mathrm{x})$, and $\mathrm{C}(0)=0$. Enterprise $\mathrm{B}$ pays $\omega(\mathrm{x})$ to purchases $\mathrm{X}$, and $\omega(0)=0$. Then the total profit function of supplier $A$ is

$$
\mathrm{R}_{\mathrm{A}}=\omega(\mathrm{x})-\mathrm{C}(\mathrm{x})
$$

In order to enhance the production efficiency, enterprise B is willing to make irreversible investment $K$ to buy and use the specific equipment, the cost of investment $K$ will be $k$, and investment $K$ would determine the total management return of enterprise $B$, the total profit function of $B$ is

$\mathrm{R}_{\mathrm{B}}=\mathrm{P}(\mathrm{x}, \mathrm{k})-\omega(\mathrm{x})-\mathrm{k}$

Then under the perfect condition, the best outcome is causes the total profit maximization of $B$ and $A$. 


$$
\begin{aligned}
& \prod=P(x, k)-\omega(x)-k+\omega(x)-C(x)=P(x, k)-C(x)-k \\
& \partial P(x, k) / \partial \mathrm{k}=1 \\
& \partial P(x, k) / \partial x=\partial C / \partial \mathrm{x}
\end{aligned}
$$

Under the best condition the marginal value of investment is equal to the marginal cost of investment, and the marginal value of $\mathrm{X}$ was equal to the marginal cost of $X$ produced by supplier $A$.

Because of imperfect market, the opportunism behaviors like hold-up are supposed between supplier A and enterprise B. After enterprise B makes investment $\mathrm{K}$, supplier $\mathrm{A}$ requests the enterprise $\mathrm{B}$ pay more to purchase $\mathrm{X}$, therefore the new negotiations have carried on. Enterprise $\mathrm{B}$ has to pay more to purchase $\mathrm{X}$ because investment $\mathrm{K}$ is irreversible and $\mathrm{k}$ becomes sunk cost. Thus, profit target of enterprise $B$ is

$\max R_{B}=\max [P(x, k)-\omega(x)]$

And profit target of supplier $A$ is

$\max \mathrm{R}_{\mathrm{A}}=\max [\omega(\mathrm{x})-\mathrm{C}(\mathrm{x})]$

According to the Nash equilibrium,

$$
\max _{\omega(x)}[P(x, k)-\omega(x)][\omega(x)-C(x)]
$$

The result is that

$$
\begin{aligned}
& \partial \mathrm{P}(\mathrm{x}, \mathrm{k}) / \partial \mathrm{x}=\partial \omega / \partial \mathrm{x}=\partial \mathrm{C} / \partial \mathrm{x} \\
& \omega(\mathrm{x})=[\mathrm{P}(\mathrm{x}, \mathrm{k})+\mathrm{C}(\mathrm{x})] / 2
\end{aligned}
$$

It shows that the total payments of enterprise $B$ to supplier $A$ is one half of the sum of total repayment of enterprise B and total cost of supplier $A$, that is to say that enterprise B and supplier A divides equally the total income if production achieved equilibrium.

Now considering the investment scale of enterprise B, substitutes $\omega(\mathrm{x})$, enterprise $B$ attains the profit is

$$
\mathrm{R}_{\mathrm{B}}=\mathrm{P}(\mathrm{x}, \mathrm{k})-\mathrm{k}=[\mathrm{P}(\mathrm{x}, \mathrm{k})-\mathrm{C}(\mathrm{x})] / 2-\mathrm{k}
$$

Because enterprise $\mathrm{B}$ can forecast this result, it will choose an investment scale to maximize own profit, that is

$$
\partial \mathrm{P}(\mathrm{x}, \mathrm{k}) / \partial \mathrm{k}=2
$$

Thus according to Nash bargaining solution, the marginal value of the investment made by enterprise $B$ should achieve two times of the capital marginal cost. As compared with the best investment, investment according to the Nash equilibrium is insufficient definitely, and will affect the production of $\mathrm{X}$ at the next stage. The market failure causes effective investment insufficient Therefore in order to obtain the more return by optimizing investment, enterprise B will implement the vertical internal integration and enter the realm of X's production. 
In above model, one side of upstream and downstream enterprises has the opportunism behavior, another side has incentive to implement the internal integration to gain the greater return. But in fact, the internal integration is one kind of choice for manufacturer to overcome the opportunism behavior. If specific management behavior except internal integration can guarantee the transaction quantity and price, the manufacturer also may enable the investment to achieve most superior.

Virtual operation is one of such management behaviors, it introduces establishing long-term cooperation relationship, concluding service agreement, setting up strategic alliance, outsourcing and so on, has formed correlative dependence and reciprocity between the transaction sides, causes a side of transaction to have the tremendous influence to opposite side even control opposite side, thus it plays the role which guarantee the transaction performed smoothly. In other words, manufacturer may obtain assuring contract through virtual operation. Daniel F. Spulber[4] has already proven: If the contract is reliable and has guaranteed, the enterprise holds or does not hold the specific property rights, all can realize the investment efficiency optimization, namely under this condition property rights are neutral. Therefore, virtual operation can replace internal integration in theory.

Reviewing the American Enterprises' development, Ford Motor Company, once was the model of internal integration management, since 1980's transformed the former internal integrated organization, and used more and more exterior transaction contracts to replace the internal organization. All manner of virtual operation and activities may show in practice that: enterprises are possible to obtain the very good economic efficiency equally even though they do not hold the property rights of certain assets. Virtual operation urges exterior market to become perfect, so may overcome the problem of market failure.

\section{An analysis of respective characteristics of internal integration and virtual operation}

Through above analysis, both virtual operation and internal integration can guarantee the inside or outside contracts, increase profits of enterprise. The form of modern enterprise's organization more and more tends toward diverseness and variety. Modern enterprise may use internal integration behavior to enhance the enterprise ability, also may adopt virtual operation to strengthen own capability to conclude and fulfill the contract by virtual market.

Enterprise adopts internal integration behavior, carries out specific investment, sets up more complicated organization, implements the common control and coordination by unified management system, so it obtains stronger transaction ability by possessing more internal resource.

Enterprise uses virtual operation, concludes and implements sorts of assuring contracts and strategic agreements, integrates interior and exterior resource, achieves sharing and controlling exterior resource, so it gains more management resource through guaranteed contracts. 
Thus it can be seen, the internal integration and virtual operation all are the ways of enterprise to enhance transaction ability and strengthen competitive advantage.They are also two approaches of enterprise to expand its organization. The way of internal integration would form a relative integrity of enterprise's organization, but the way of virtual operation would form the loose structure of enterprise's organization(virtual organization).

The superiorities of virtual operation to internal integration are: virtual operation 1 ealize interior and exterior resources of the enterprise sharing and optimizing, $\mathrm{r}$ e business risk by lessening specific investments and overcoming or ${ }_{\xi}$ zation's rigidity, and virtual operation can help firms to enhance ability to con de and fulfill transaction contract as more exterior assets and resources of firms zould be used in key business's activities. Certainly, virtual operation is inferior to internal integration in controlling transaction contract.

Internal integration behavior takes out interior market and uses it, but virtual operation establishes perfect exterior market(virtual market) and uses it. Interior market and exterior market have each own characteristic. Internal integration improves semifinished products and factors trade through constructing interior market, spurs exterior market to become perfect; virtual operation colligates exterior and interior market, increases efficiency of transaction. Although virtual operation does not have the absolute right to control the transaction contract, it has the flexibility actually to choose the manner and object of contract.

Each kind of enterprises cultivate their own competitive advantage depended on constructing and using interior market and exterior market. The conducts to construct market change structure of market, including constructing exterior and interior market, establishing a new market and alter estate of existing market, shifting a imperfect market to a perfect market. The conducts to use market utilize all sorts of market, including using exterior market, virtual market and interior market, making use of perfect market and imperfect market. Virtual operation can construct a relatively perfect exterior market(virtual market), also use existing exterior market efficiently, so enterprises are able to control market and save transaction cost through virtual operation.

\section{The study on the correlative factors of virtual en terprises}

In order to develope rapidly, enterprises should use more exterior resources with the aid of other enterprises by virtual operation. But effective virtual operation is restricted by many conditions. The study on the correlative factors of virtual operation is the key to do basic work and virtual operating scientifically. The correlative factors of virtual enterprises includes the interior conditions of enterprises and exterior conditions from the dimensionalities of micro-environment and macroenvironment.

The interior conditions of virtual operation consist of the competitive advantage of structure, the competitive advantage of ability, informationalization of enterprises and harmony of innovation and control competence. In the competitive advantage of structure, the competitive advantage theory of Porter[5] expatiates orientation of 
enterprises in the chain of value and make use of the three principles of competitive advantage and the relevance theory of enterprises to enhance competitive advantage of enterprises, so as to improve virtual operation. The competitive advantage of ability lays stress on important effect of nuclear abilities in virtual operation. The conformity of nuclear abilities guarantees success of virtual operation, only the enterprises with some nuclear abilities can be received as virtual members by other enterprises. In addition, the strategy transformation from multielement to refocusing reflects the strategic demand of change of market environment and business process reengineering of enterprises, which is the inevitable choice of enterprises to meet the competitive advantage of ability. Informationalization of enterprises can benefit their nuclear competitiveness to operate virtually, can favor cooperation with virtual partners to develop cooperation advantage, and can profit informationalization and management innovation of enterprises to better virtual operation. The adaptive business process based enterprises should look beyond the traditional enterprises and marketplaces through collaborative interactions and dynamic e-business solution bindings. The harmony of innovation and control competence can guarantee rational operation of enterprises, so does virtual operation. The harmony of innovation and control competence can improve nuclear abilities of enterprises; so, the "degree" in virtual operation and all kinds of its manifestation should unify competitiveness of innovation and control dynamically.

Exterior conditions can be divided into credit, national informationalization, logistics, and legal environment. Credit can reduce transaction cost to remedy market risk which is resulted from incompleteness of contracts and uncertainty of market, can eliminate information asymmetry to enhance operation efficiency of enterprises so as to guarantee virtual operation. Virtual operation is based on credit and enterprise may give more credit to other enterprises through virtual operation. National informationalization provides a platform for virtual operation, besides, development of information industry, popularization of network and development of electronic commerce and electronic government administration are the indispensable conditions, these conditions can improve the management and exchange of information in each enterprise and among enterprises. Logistics provides the channel of shared information and resources for virtual operation, supply chain management should build the coordination mechanism between upstream and downstream enterprises to guarantee virtual operation by effective logistics, both informationalization and logistics are inter-determined. Legal environment guarantees smooth virtual operation, which impenetrate the whole process of virtual operation. Along with the rapid development of virtual operation, a great deal of legal problems emerged. The legal environment is the safeguard for virtual operation, whole process of virtual operation including the market opportunity recognition, the partner enterprises choice, negotiations with partner, conclude and fulfill the contract, needs correlative legal.

The enterprises carry out virtual operation restricted by interior and exterior conditions, therefore, along with the changes of market, environment, competition and enterprises' strategy, being agile and taking dynamic integration or virtual operation should be the best policy of enterprises' organization. 


\section{Conclusion}

In term of above analysis, virtual operation and internal integration are two parallel ways which enterprises may choose to expand their organization. Virtual operation urges exterior market to become perfect, so may overcome the problem of market failure. Virtual operation can construct a relatively perfect exterior market, also can use existing exterior market efficiently, so enterprises are able to control market and transaction through virtual operation. But effective virtual operation is restricted by many conditions. The correlative factors of virtual enterprises includes the interior conditions of enterprises and exterior conditions from the dimensionalities of microenvironment and macro-environment. Therefore, along with the changes of market, environment, competition and enterprises' strategy, being agile and taking dynamic integration or virtual operation should be the best policy of enterprises' organization.

\section{References}

1. N. Rackham, L. Friedman and R. Ruff, Getting Partnering Right: How Market Leaders are Creating Long-term Competitive Advantage, McGraw Hill Publications, New York(1996),

2. R. H. Coase, "The Nature of the Firm", Economica. 4, 386-405(1937).

3. C. P. Kindleberger, "The 'New' Multinationalization of Business", ASEAN Economic Bulletin., 5, 113-124(1996).

4. D. F. Spulber, Market Microstructure: Intermediaries and the Theory of the Firm, Cambridge University Press, New York,(1999).

5. M. Porter, Competitive Advantage, Free Press, New York(1985).

6. R. Jaikumar, "Post Industrial Manufacturing", Harvard Business Review, 86, 69-76(1986).

7. S. J. Grossman and O. Hart, "The Costs and Benefits of Ownership: A Theory of Vertical and Lateral Integration", Journal of Political Economy ,94, 691719(1986). 